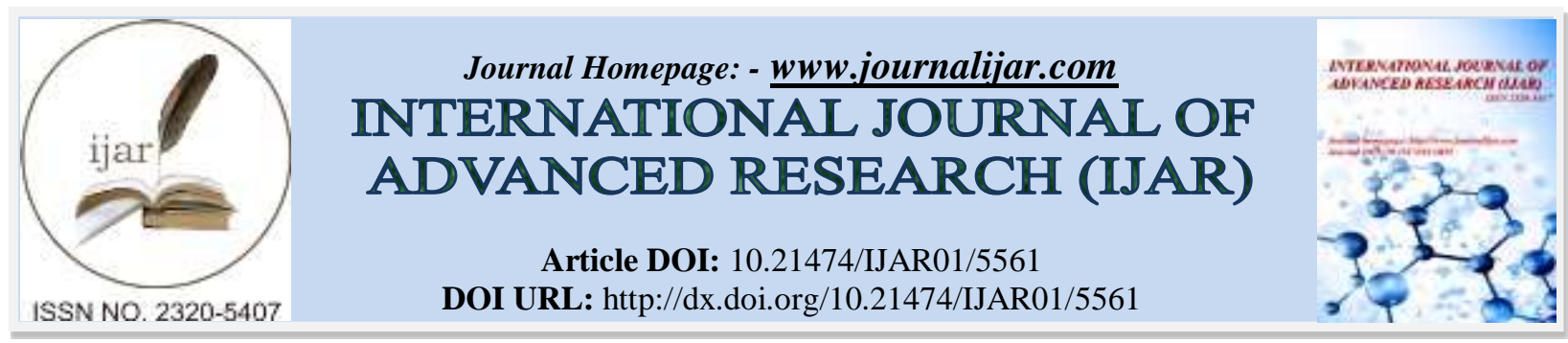

RESEARCH ARTICLE

\title{
PROBIOTIC EFFECTS IN LIVER CIRRHOSIS, INDUCED BY THIOACETAMIDE IN RATS, STATUS WIDESPREAD IN EGYPT AND SUDAN.
}

\author{
Amal Yousef Mohamed, Hassan. M. Sobhy, Wafai. Z. A. Mikhail, Shendy M. S, Al_Banna. N. H and \\ M. A. Kassem. \\ Animal Reources. Natural Resources Department, African Research And Studies. Cairo University.
}

\section{Manuscript Info}

Manuscript History

Received: 07 August 2017

Final Accepted: 09 September 2017

Published: October 2017

\section{Abstract}

Liver cirrhosis is an increasing cause of morbidity and mortality in more developed countries So, the aim of the present study is to verify the effects of Probiotics in cirrhotic rats status. For this purposes Thirty male albino rats, were fed on basal diet and were divided into two groups and were induced liver cirrhosis by thioacetamide, The group (2) were given orally Lactobacillus acidophilus $\left(10^{8} \mathrm{cfu} / \mathrm{ml}\right)$ daily. Group (2) that given orally Lactobacillus acidophilus were better than group (1) in there results of histopathology and in there results of liver functions. The use of probiotics as found to have a protective effect against liver cirrhosis induced by thioacetamide in rats.

Copy Right, IJAR, 2017,. All rights reserved.

\section{Introduction:-}

Cirrhosis is an increasing cause of morbidity and mortality in developing countries including Egypt and Sudan. Hospital-based analyses indicate that acute viral hepatitis, chronic hepatitis, cirrhosis and hepatocellular carcinoma are responsible for at least 12 percent of medical admissions and over 20 percent of hospital mortality in many parts of Africa. (Egyptian national control strategy for viral hepatitis 2008-2012; mahmoud, 2013).

Thioacetamide (TAA) - induced liver cirrhosis has been widely studied in rats and in other animal species and showed pathology similar to the most common human liver diseases (Cascades and Martin-Sanz., 1991).

Probiotics are dietary supplements containing potentially beneficial bacteria or yeasts. Strains of the Lactobacillus and Bifidobacterium, are the most widely used probiotic bacteria. They have been used for centuries in the form of dairybased fermented products. Medical conditions that have been reportedly treated or have the potential to be treated with probiotics include diarrhea, gastroenteritis, irritable bowel syndrome, and inflammatory bowel disease (Crohn's disease and ulcerative colitis), cancer, depressed, immune function, inadequate lactase digestion, infant allergies, failure-to-thrive, hyperlipidemia, hepatic diseases, Helicobacter pylori infections and genitourinary tract infections. (Tannock, 2003).

The aim of the present study is to verify the effects of Probiotics in liver cirrhosis induced by thioacetamide in rats.

\section{Materials:-}

Lactobacillus acidophilus La-5, Chr. Hansen used in this animal study was obtained from (Misr Food Additives Company), Egypt. Type of bacterial growth medium is named by its inventors de Man, Rogosa and Sharpe (MRS) 
broth and MRS agar was obtained from Oxoiod Company, Egypt. A total of 30 male albino rats, Sprague Dawley strain, weighing $80 \pm 10 \mathrm{~g}$ was obtained from the Laboratory of Animal Colony, Helwan, Cairo. Casein, cellulose, vitamins, minerals, was obtained from the General Company for Commerce and Chemicals, Egypt. Thioacetamide (TAA) was obtained from the El-Gomhoria Company for Chemicals, Egypt.

\section{Methods:-}

Preparation of bacterial suspension:-

Five gm from of freeze dried Lactobacillus acidophilus were mixed with $45 \mathrm{ml}$ of sterile MRS broth in sterile Erlenmyr's flask and incubated anaerobically at $37^{\circ} \mathrm{C}$ for $48-72 \mathrm{hrs}$. Counting the colony forming unit per ml of the incubated broth was performed for Lactobacillus acidophilus using MRS agar which was incubated at $37{ }^{\circ} \mathrm{C}$ for 48 $72 \mathrm{hrs}$. Dilution was made for microorganisms in 1 liter of brain heart infusion broth to give final concentration of $10^{8}$ (colony-forming unit) $\mathrm{CFU} / \mathrm{ml}$. Prepared bacterial suspension were stored at $4^{\circ} \mathrm{C}$ till the beginning of the experiment (Heon et al., 2007).

\section{Experimental design:-}

Thirty male albino rats, Sprague Dawley strain, weighing (180 \pm 10 gm) were be housed in well-aerated wire cages. All animals were kept under normal healthy condition and were fed on basal diet for one week for adaptation. The basal diet $(\mathrm{gm} / \mathrm{kg}$ diet ) consisted of $140 \mathrm{gm}$ casein (> 80\% protein), $100 \mathrm{gm}$ sucrose, $50 \mathrm{gm}$ corn oil, $50 \mathrm{gm}$ cellulose, $35 \mathrm{gm}$ mineral mixture, $10 \mathrm{gm}$ vitamin mixture, $1.8 \mathrm{gm}$ L-cystine, $2.5 \mathrm{gm}$ cholinebitartrate and the remainder was corn starch. Diets were formulated according to (Reeves et al., 1993).

After the adaptation period, rats were induced liver cirrhosis by thioacetamide and was divided into two groups, the first group (15 rats) was considered as control group and the second group (15 rats) were given orally Lactobacillus acidophilus $\left(10^{8} \mathrm{cfu} / \mathrm{ml}\right)$ daily in addition to thioacetamide.

At the end of the experimental period (16 weeks), rats were fasted overnight before sacrificing. Blood samples were collected in dry clean centrifuge tube and left for 15 minutes to clot at room temperature, then centrifuged for a 15 minutes at $3000 \mathrm{rpm}$ to separate the serum. Serum was carefully separated and transferred into dry clean tubes and kept frozen at $20^{\circ} \mathrm{C}$ till analysis. Liver for each rat was collected and immersed in $10 \%$ neutral buffered formalin as fixative for histopathological examination according to, in Veterinary Medicine College, Cairo University.

AST and ALT were estimate by colorimetric method. Total and direct bilirubin, and albumin were estimated in rat serum also at end of exepirement.

\section{Results:-}

It was found that GOT was significantly higher in cirrhotic rats not given probiotic compared to those given probiotic $70 \mathrm{U} / \mathrm{L}$ vs. $41.5 \mathrm{U} / \mathrm{L}(p<0.001)$.

Regarding GPT, despite it was found higher in those not given probiotic than those given probiotic, this difference didn't reach statistical significance $18.8 \mathrm{U} / \mathrm{L}$ vs. $14.75 \mathrm{U} / \mathrm{L}(\mathrm{p}>0.05)$.

No significant differences were found regarding bilirubin and albumin between the two groups.

Regarding the histopathology, many items were studied after scarifying rats and staining with $\mathrm{H}$ and $\mathrm{E}$ with magnification of 100-400 under light microscopy. Focal hepatic necrosis was founded less marked in the group treated with probiotic compared to the group not given probiotic. Similarly, ballooning and hydropic degeneration of hepatocytes were more extensive in the rat group not given probiotic compared to that given probiotic. Similar differences were observed regarding oval cell proliferation and hyperplasia. Apoptosis, kariomegaly, presence of multiple large nucleoli in hepatocytes also were extensive in group 1 not given probiotic. Also development of thick intralobular fibrotic strands and fibroblast proliferation around hepatocytes were less marked in group 2 treated with probiotic. Similarly collagen fiber deposition in portal area was less marked in group2. New bile ductile formation, proliferation and dysplasia were found more extensive in group 1 not given probiotic. In this study, also we found that the use of probiotics decreased necrosis, collagen deposition, produced thinner fibrous strands and less severity and all pathological criteria in general, compared to rats which were not treated with probiotics. Thus, probiotics were found to have a protective effect against cirrhosis induced by thioacetamide in rats. 


\section{Conclusion and recommendations:-}

From the results of this study it is concluded that probiotics might have a considerable beneficial effects in rat cirrhosis induced by thioacetamide regarding some biochemical parameters and histopathology. Translation of these results and studying probiotics in human with different liver disease may help to protect these patients in the future.

Therefore it is recommended to do more studies on larger number of rats and on patient with different liver diseases.

\section{Reference:-}

1. Cascades M, Martin-Sanz P, Craciunescu DG, Mayo I, Aguilar A, RoblesChillida, EM and Cascales C (1991): Alterations in hepatic peroxidation mechanisms in thioacetamide-induced tumors in rats. Effect of a rhodium (III) complex. Carcinogenesis, 12: 233-240.

2. EGYPTIAN NATIONAL CONTROL STRATEGY FOR VIRAL HEPATITIS (2008-2012): Arab Republic of Egypt, Ministry of Health and Population National Committee for the Control of Viral Hepatitis.

3. Heon PY, Kim JG, Shin YW, Kim S H and Whang K Y (2007): Effect of Dietary Inclusion of Lactobacillus acidophilus ATCC 43121 on Cholesterol Metabolism in Rats. J. Microbiol. Biotechnol. 17, 4: 655- 662.

4. Mahmoud M (2013): Evaluation of Hemostaitc Parameters of Sudanese patients with liver Disease. attending Khartoum Teaching Hospital Egypt. Acad. J. biolog. Sci. 5. (1): 1-5.

5. Reeves P, Nielsen F and Fahmy G (1993): Reported of the American Institute of Nutrition; committee on the reformulation of the AIN76, A rodent diet. J Nutrition. 123:1939-51.

6. Tannock GW (2003): Probiotics: time for a dose of realism. Curr Issues IntestMicrobiol. 4. (2): 33-42 . 